\title{
Peri-operative data on the nuss procedure in children with pectus excavatum: independent survey of the first 20 years' data Aristotle D Protopapas* and Thanos Athanasiou
}

\author{
Address: Department of Biosurgery \& Surgical Technology, Imperial College London, St. Mary's Hospital, London, W2 1NY, UK \\ Email: Aristotle D Protopapas* - aristotelis.protopapas02@ic.ac.uk; Thanos Athanasiou - thanos.athanasiou@ic.ac.uk \\ * Corresponding author
}

Published: 4 July 2008

Journal of Cardiothoracic Surgery 2008, 3:40 doi:10.1 I86/I749-8090-3-40

Received: 20 March 2008

Accepted: 4 July 2008

This article is available from: http://www.cardiothoracicsurgery.org/content/3/I/40

(C) 2008 Protopapas and Athanasiou; licensee BioMed Central Ltd.

This is an Open Access article distributed under the terms of the Creative Commons Attribution License (http://creativecommons.org/licenses/by/2.0), which permits unrestricted use, distribution, and reproduction in any medium, provided the original work is properly cited.

\begin{abstract}
Objective: To review the literature and assess the cumulative data on the Nuss operation in children on its twenty years' anniversary: The Nuss procedure corrects the pectus excavatum by minimal access semi-permanent insertion of metal bars in order to reduce the deformity and refashion the contour of the growing thorax. The advantage over previous techniques is avoidance of osteochondrotomies and thence allowance for normal growth of the thorax.
\end{abstract}

Study design: PubMed search was performed. Primary outcomes were mortality, morbidity and individual complications. Secondary outcomes were procedure time and hospital stay.

Results: We merged the data from 19 reports comprising 1949 children of mean age 10.6 years.

No mortality was observed and the procedure was associated with morbidity of $15.4 \%$. The commonest complications are bar-related adverse events (5.7\%) and pneumothorax (3.5\%). The average procedure time and the average hospital stay were 68 minutes and 5.5 days respectively.

Conclusion: 20 years of initial evidence suggests that the Nuss group of procedures is a safe minimal access option for correction of pectus excavatum in childhood.

\section{Introduction}

The cardiothoracic surgeons are moving towards minimally invasive techniques. Such a technique is the Nuss repair (alias Minimally Invasive Repair of Pectus Excavatum or Miniature Access Pectus Excavatum Repair) for pectus excavatum (funnel chest) [1], the commonest chest wall anomaly in humans [2], first described in 1594 by Johannes Schenk, occurring in approximately 1 in every 400 births, males being afflicted 5 times more often than females. The indication for correction is primarily cosmetic, although the potential for cardiorespiratory improvement can be considered.
The original Nuss technique has being previously described $[1,24]$. Its principle is the permanent reduction of the bone deformity by insertion of one (or more) malleable metal bars in order to refashion the contour of the growing thorax.

Advantages and disadvantages of the Nuss in relation to open techniques (such as Ravitch [2] and Willital-Hegemann that include extensive thoracic incisions and multiple thoracic osteochondrectomies (resections of ribs and cartilage) are presented in Table 1.

The principal advantage over these techniques is avoidance of osteochondrotomies and thence allowance for 
Table I: Perceived advantages and disadvantages of minimal access strategy for correction of pectus in childhood in comparison to pre-existing conventional techniques

\begin{tabular}{cc}
\hline Advantages & Disadvantages \\
\hline $\begin{array}{c}\text { Short hospital stay } \\
\text { Minimal trauma }\end{array}$ & $\begin{array}{c}\text { Cost of thoracoscopy and equipment } \\
\text { Second procedure for bar removal } \\
\text { Capnothorax in thoracoscopy }\end{array}$ \\
\hline
\end{tabular}

normal growth of the thorax, as subperichondral resection of the costal cartilages may halt the growth of the thoracic cage in toddlers and adolescents.

The metalwork is later removed as a day-case operation (nor requiring overnight stay in hospital) under general anaesthesia.

The Nuss operation can be performed with or without use of thoracoscopy. The selection of age for the Nuss varies with clinical, personal and socio-economical reasons (such as change of school and fear of intimidation by new peers), while removal of bars is scheduled within two to three years from the insertion. In Britain, some surgeons prefer to perform Nuss around the age of 10, before the child changes schools and thence is exposed to new peers. Some other surgeons will perform Nuss earlier, deciding on parental preference and individual clinical circumstances.

\section{Materials and methods}

We searched the literature with a simple strategy:

PubMed search

Last Date performed: 31 December 2006

Search keyword 'Nuss', language English, Humans, children

Cross-validation by hand search to identify case series and exclude isolated case reports.

Primary outcomes: Mortality, morbidity, individual complications

Secondary outcomes: Procedure time and hospital stay.

Descriptive and summary statistics were performed. Denominators were related to actual data. Missing data were not defaulted.

Table 2: The series merged, 20 years of Nuss operations in children 1987-2006

\begin{tabular}{|c|c|c|c|c|}
\hline $\begin{array}{l}\text { Reference } \\
\text { number }\end{array}$ & $\begin{array}{l}\text { Patients } \\
\text { operated }\end{array}$ & Type of study & $\begin{array}{c}\text { Number of } \\
\text { centres }\end{array}$ & Comment \\
\hline 1 & 329 & Retrospective & One & Series update on ref. 24 \\
\hline 3 & 21 & Comparative & One & \\
\hline 4 & 52 & Retrospective & One & \\
\hline 5 & 335 & Retrospective & One & Encompasses ref. 19 \\
\hline 6 & 53 & Retrospective & One & \\
\hline 10 & 22 & Retrospective & One & \\
\hline 11 & 40 & Retrospective & Not reported & \\
\hline 12 & 172 & Retrospective & Eight & \\
\hline 13 & 31 & Retrospective & One & \\
\hline 15 & 20 & Retrospective & One & Modified technique \\
\hline 16 & 36 & Comparative & One & \\
\hline 23 & 27 & Retrospective & One & Subgroup of all-age cohort \\
\hline $8^{*}$ & 107 & Comparative & One & Similar data to ref. 9 \\
\hline 9* & 107 & Retrospective & Not reported & Similar data to ref. 8 \\
\hline 14 & 80 & Comparative & One & \\
\hline $17 * *$ & 35 & Comparative & One & Same centre as ref. 18 \\
\hline $18^{* *}$ & 21 & Retrospective & One & Same centre as ref. 17 \\
\hline 22 & 461 & Retrospective & One & \\
\hline Total & 1949 & & & \\
\hline
\end{tabular}




\section{Results}

\section{Selection of reports}

18 series of Nuss on children were identified (Table 2), originating from one or more of seven countries, or one of five of the United States of America.

Of these, there were at least three reports preceded by others with apparently overlapping cohorts, [2] by [20,3] by [13] and [14,5] by [19] so we utilised data from the larger and more up to date ones $[2,3,5]$.

Interestingly, two reports from neighbouring countries [Japan, South Korea, $[8,9])$ over a similar period had the same number of subjects (107 each), similar but not identical demographics (age, gender) and similar outcomes. Both reports have being included separately in our survey. Two reports from the same centre seemed to report on separate cohorts $[17,18]$ and have being also included separately in our survey.

\section{Demographics (Table 3)}

1949 children have had Nuss operations. Mean age was 10.6 years, ratio male: female 77:23.

\section{Morbidity and Mortality}

No mortality was observed and the incidence of morbidity was $15.4 \%$. The most commonly reported complications were:

1. Bar-related events (bar displacement requiring revision) (111 events, incidence 5.7\%) and
2. Pneumothorax (68 events including those treated without chest drain, overall incidence 3.5\%).

The incidence of wound infection was $2.2 \%$, the incidence of other pleuropulmonary complications including effusions and atelectasis/pneumonia was $2 \%$. Other complications were less common (Table 4).

\section{Other Perioperative Data}

The average length of operation in minutes was $68 \mathrm{~min}$ utes (range 28-200).

Average Hospital stay was 5.5 days (range 2-27 days).

\section{Conclusion}

We hope that this brief independent survey will offer the necessary peri-operative data on this now well-established cosmetic intervention in children: The Nuss procedure has been performed all around the world with no reported mortality for 20 years (1987-2007), indicated primarily for cosmesis in the paediatric sufferer of pectus excavatum. Potential cardiorespiratory improvement is not as yet confirmed, whilst the co-existence of Marfan's syndrome can be ruled out by pre-operative echocardiography.

The variations of the Nuss procedure stem from thoracoscopic or open, and then thoracoscopy with single or double-lumen ventilation (in toddlers double lumen ventilation may be cumbersome given their tracheal size).

Table 3: Cumulative perioperative data on 20 years of Nuss operations in children 1987-2006

\begin{tabular}{|c|c|c|c|c|}
\hline $\begin{array}{c}\text { Reference } \\
\text { number }\end{array}$ & $\begin{array}{l}\text { Patient } \\
\text { number }\end{array}$ & Average Age & $\begin{array}{c}\text { Average } \\
\text { Operating } \\
\text { Time }\end{array}$ & $\begin{array}{c}\text { Average } \\
\text { Hospital Stay }\end{array}$ \\
\hline I & 329 & II years & Not reported & 5 days \\
\hline 3 & 21 & 14.4 years & $53^{\prime}$ & Not reported \\
\hline 4 & 52 & Unknown & $106^{\prime}$ & 3.9 days \\
\hline 5 & 335 & 8 years & Not reported & Not reported \\
\hline 6 & 53 & 9 years & $76^{\prime}$ & 8.9 days \\
\hline 10 & 22 & 15.5 years & Not reported & 13.4 days \\
\hline 11 & 40 & I 7.6 years & $126^{\prime}$ & Not reported \\
\hline 12 & 172 & I5.I years & $76^{\prime}$ & Not reported \\
\hline 13 & 31 & 14.5 years & Not reported & 4 days \\
\hline 15 & 20 & 14 years & $75^{\prime}$ & 5.5 days \\
\hline 16 & 36 & 12.3 years & $96^{\prime}$ & 5.5 days \\
\hline 8 & 107 & 7.9 years & $67^{\prime}$ & 8 days \\
\hline 9 & 107 & 7.5 years & $48^{\prime}$ & Not reported \\
\hline 14 & 80 & II.5 years & $53^{\prime}$ & 3.7 days \\
\hline 17 & 35 & 9.5 years & $198^{\prime}$ & 4.8 days \\
\hline 18 & 21 & 8.2 years & Not reported & 4.9 days \\
\hline 22 & 461 & 15.2 years & $52^{\prime}$ & 5.3 days \\
\hline 23 & 27 & 5.9 years & $52^{\prime}$ & 4.9 days \\
\hline Total & 1949 & 10.6 years & 68' & 5.5 days \\
\hline
\end{tabular}


Table 4: Complications of 20 years of Nuss operations in children 1987-2006

\begin{tabular}{cc}
\hline Complication & Cumulative \\
\hline Bar-related adverse events & $111(37 \%)$ \\
Pneumothorax & $68(23 \%)$ \\
Other Pleuropulmonary, except pneumothorax & $39(13 \%)$ \\
Wound infection & $43(14 \%)$ \\
Pericardial effusion & $28(9 \%)$ \\
Hemothorax & $12(4 \%)$ \\
\hline Total & 301 \\
\hline
\end{tabular}

Bar stabilisers have evolved as a valid addition to the technique [11].

Pneumothorax and bar-related events (pain, dislocation or infection) may complicate the procedure and are the primary post operative points of concern. Pneumothorax is as expected, commoner with thoracoscopy: the technique may involve carbon dioxide insufflation (capnothorax [25] where single lumen tracheal intubation is utilised.

Our observations reinforce these of a previous smaller multi-centre cumulative report on 251 cases 7 years ago [21] and a recent case review by the inventor of the technique [24].

The advantages of this procedure include the following: the short hospital stay and limited invasion surgery which allows for growth in the skeleton as opposed to the ostochondrectomies (Table 1). On the balance is the obvious cost of the thoracoscopy and specialised equipment as well as the second outpatient-day case procedure of removal of the bar(s).

We have now reached the point of adequate experience with Nuss that the purchasers may decide on strategies after careful individual cost-effectiveness assessment. Most workers timed the operation at an age appropriate to the cosmetic expectations of the patient and family considering the growth spurt of teenagers, namely prior to the early teens. It is not unusual to perform Nuss in young adults as a matter of surgeon's and patient's preference, where care should be exercised for the bar recipient not to be exposed to vigorous activity prior to removal of the bar as displacement is a recognised complication associated with contact sports, trauma or intense manual labour[26].

\section{Limitations of the study and future research}

Not all reported series include the data for the variables studied, the length of postoperative in-hospital stay being one important one. This might have an impact on the results. Post operative hospital stay is a surrogate index of performance, especially in paediatric populations. It is evident in the literature that the available data have not been based in comparative high quality studies and patient based outcomes such as Health Related Quality of life and patient satisfaction which are important considerations in therapeutic decision making. Also the long-term results of the procedure are not being discussed in this paper.

\section{Competing interests}

The authors declare that they have no competing interests.

\section{Authors' contributions}

$\mathrm{AP}$ conceived the research idea and drafted the manuscript. TA corrected the manuscript. Both authors read and approved the final manuscript.

\section{References}

I. Nuss D, Croitoru DP, Kelly RE Jr, Goretsky MJ, Nuss KJ, Gustin TS: Review and discussion of the complications of minimally invasive pectus excavatum repair. Eur J Pediatr Surg 2002, I 2(4):230-4.

2. Huddleston CB: Pectus excavatum. Semin Thorac Cardiovasc Surg 2004, 1 6:225-32.

3. Boehm RA, Muensterer OJ, Till H: Comparing minimally invasive funnel chest repair versus the conventional technique: an outcome analysis in children. Plast Reconstr Surg 2004, I | 4(3):668-73. discussion 674-5.

4. Zallen GS, Glick PL: Miniature access pectus excavatum repair: Lessons we have learned. J Pediatr Surg 2004, 39(5):685-9.

5. Park HJ, Lee SY, Lee CS: Complications associated with the Nuss procedure: analysis of risk factors and suggested measures for prevention of complications. J Pediatr Surg 2004, 39:391-5.

6. Watanabe A, Watanabe T, Obama T, Ohsawa H, Mawatari T, Ichimiya $Y$, et al:: The use of a lateral stabilizer increases the incidence of wound trouble following the Nuss procedure. Ann Thorac Surg 2004, 77(I):296-300.

7. Ohno K, Morotomi Y, Ueda M, Yamada H, Shiokawa C, Nakaoka T, et al: Comparison of the Nuss procedure for pectus excavatum by age and uncommon complications. Osaka City Med J 2003, 49(2):7I-6.

8. Jo WM, Choi YH, Sohn YS, Kim HJ, Hwang JJ, Cho SJ: Surgical treatment for pectus excavatum. J Korean Med Sci 2003, I 8:360-4.

9. Uemura S, Nakagawa Y, Yoshida A, Choda Y: Experience in 100 cases with the Nuss procedure using a technique for stabilization of the pectus bar. Pediatr Surg Int 2003, I9(3): I86-9.

10. Haecker FM, Bielek J, von Schweinitz D: Minimally invasive repair of pectus excavatum (MIRPE) - the Basel experience. Swiss Surg 2003, 9(6):289-95.

II. Schaarschmidt K, Kolberg-Schwerdt A, Dimitrov G, Straubeta J: Submuscular bar, multiple pericostal bar fixation, bilateral thoracoscopy: A modified Nuss repair in adolescents. J Pediatr Surg 2002, 37(9): 1276-80.

12. Hosie S, Sitkiewicz T, Petersen C, Gobel P, Schaarschmidt K, Till H, et al.: Minimally invasive repair of pectus excavatum - the Nuss procedure. A European multicentre experience. Eur J Pediatr Surg 2002, I 2(4):235-8.

13. Jacobs JP, Quintessenza JA, Morell VO, Botero LM, van Gelder HM, Tchervenkov $\mathrm{Cl}$ : Minimally invasive endoscopic repair of pectus excavatum. Eur J Cardiothorac Surg 2002, 2 I (5):869-73.

14. Miller KA, Woods RK, Sharp RJ, Gittes GK, Wade K, Ashcraft KW, et al:: Minimally invasive repair of pectus excavatum: a single institution's experience. Surgery 200I, I30(4):652-7. discussion 657-9.

15. Hebra A, Gauderer MW, Tagge EP, Adamson WT, Othersen HB Jr: A simple technique for preventing bar displacement with the Nuss repair of pectus excavatum. J Pediatr Surg 2001, 36(8): 1266-8. 
16. Wu PC, Knauer EM, McGowan GE, Hight DW: Repair of Pectus Excavatum Deformities in Children: A New Perspective of Treatment Using Minimal Access Surgical Technique. Arch Surg 200I, 136(4):419-424.

17. Molik KA, Engum SA, Rescorla FJ, West KW, Scherer LR, Grosfeld JL: Pectus excavatum repair: experience with standard and minimal invasive techniques. J Pediatr Surg 200I, 36(2):324-8.

18. Engum S, Rescorla F, West K, Rouse T, Scherer LR, Grosfeld J: Is the grass greener? Early results of the Nuss procedure. J Pediatr Surg 2000, 35(2):246-5I.

19. Park HJ, Lee SY, Lee CS, Youm W, Lee KR: The Nuss procedure for pectus excavatum: evolution of techniques and early results on 322 patients. Ann Thorac Surg 2004, 77(I):289-95.

20. Croitoru DP, Kelly RE Jr, Goretsky MJ, Lawson ML, Swoveland B, Nuss D: Experience and modification update for the minimally invasive Nuss technique for pectus excavatum repair in 303 patients. J Pediatr Surg 2002, 37(3):437-45.

21. Hebra A, Swoveland B, Egbert M, Tagge EP, Georgeson K, Othersen $\mathrm{HB} J \mathrm{r}$, et al: Outcome analysis of minimally invasive repair of pectus excavatum: review of 25 I cases. J Pediatr Surg 2000, 35(2):252-7.

22. Dzielicki J, Korlacki W, Janicka I, Dzielicka E: Difficulties and limitations in minimally invasive repair of pectus excavatum-6 years experiences with Nuss technique. Eur J Cardiothorac Surg 2006, 30(5):80I-4.

23. Kim DH, Hwang J], Lee MK, Lee DY, Paik HC: Analysis of the Nuss Procedure for Pectus Excavatum in Different Age Groups. Ann Thorac Surg 2005, 80(3): 1073-7.

24. Nuss D: Recent experiences with minimally invasive pectus excavatum repair "Nuss procedure". Jpn J Thorac Cardiovasc Surg 2005, 53:338-44.

25. Peden CJ, Prys-Roberts C: Capnothorax: Implications for the anaesthetist. Anaesthesia I99I, 48:664-6.

26. Schalamon J, Pokall S, Windhaber J, Hoellwarth M: Minimally invasive correction of pectus excavatum in adult patients. J Thorac Cardiovasc Surg 2006, I32(3):524-9.

Publish with Bio Med Central and every scientist can read your work free of charge

"BioMed Central will be the most significant development for disseminating the results of biomedical research in our lifetime. "

Sir Paul Nurse, Cancer Research UK

Your research papers will be:

- available free of charge to the entire biomedical community

- peer reviewed and published immediately upon acceptance

- cited in PubMed and archived on PubMed Central

- yours - you keep the copyright
BioMedcentral 